\title{
Visibilidad y promoción del patrimonio minero en algunos geoparques españoles
}

\author{
María del Carmen Cañizares Ruiz
}

Universidad de Castilla-La Mancha. Departamento de Geografía y Ordenación del Territorio mcarmen.canizares@uclm.es

\section{Resumen}

Los restos derivados de las actividades mineras, tanto materiales como inmateriales, se han sometido a un creciente proceso de valorización patrimonial que ha permitido sustentar iniciativas culturales relevantes (museos mineros, parques mineros, etc.). Analizamos aquí el patrimonio minero en el contexto de los geoparques Unesco. El objetivo es favorecer una mejor visibilidad del patrimonio minero aprovechando la «marca» que ofrecen los geoparques, al integrar las actividades de turismo minero dentro de las geoturísticas. La metodología utilizada parte principalmente de la revisión bibliográfica y de la consulta de la información ofrecida por los geoparques sobre la promoción turística. Los resultados se centran en una revisión teórica de la importancia del patrimonio minero a partir de las actuaciones en los geoparques: Cabo de Gata-Nijar, Sierra Norte de Sevilla, VilluercasIbores-Jara y Cataluña Central.

Palabras clave: patrimonio minero; patrimonio geológico; geoparques; turismo minero; geoturismo

Resum. Visibilitat i promoció del patrimoni miner en alguns geoparcs espanyols

Les restes derivades de les activitats mineres, tant materials com immaterials, s'han sotmès a un procés creixent de valorització patrimonial que ha permès sustentar iniciatives culturals rellevants (museus miners, parcs miners, etc.). Analitzem aquí el patrimoni miner en el context dels geoparcs Unesco. L'objectiu és afavorir-ne una visibilitat més gran aprofitant la «marca» que ofereixen els geoparcs, en integrar les activitats de turisme miner dins de les geoturístiques. La metodologia utilitzada parteix principalment de la revisió bibliogràfica i de la consulta de la informació oferta pels geoparcs sobre la promoció turística. Els resultats se centren en una revisió teòrica de la importància del patrimoni miner a partir de les actuacions en els geoparcs: Cap de Gata-Níjar, Serra Nord de Sevilla, Villuercas-Ibores-Jara i Catalunya Central.

Paraules clau: patrimoni miner; patrimoni geològic; geoparcs; turisme miner; geoturisme 
Résumé. Visibilité et promotion du patrimoine minier dans certains géoparcs espagnols

Les vestiges issus des activités minières, matérielles ainsi qu’immatérielles, ont fait l'objet d'un processus croissant de valorisation patrimoniale qui a permis de pérenniser des initiatives culturelles pertinentes (musées miniers, parcs miniers, etc.). Nous analysons ici le patrimoine minier dans le cadre des géoparcs Unesco. L'objectif est de promouvoir une meilleure visibilité du patrimoine minier en profitant de la "marque " que les géoparcs offrent lors de l'intégration des activités de tourisme minier au sein des activités géotouristiques. La méthodologie utilisée part principalement de la révision bibliographique et de la consultation de l'information offerte par les géoparcs sur la promotion du tourisme. Les résultats sont centrés sur un examen théorique de l'importance du patrimoine minier à partir des actions présentées dans les géoparcs : Cabo de Gata-Nijar, Sierra Norte de Séville, Villuercas-Ibores-Jara et Catalogne centrale.

Mots-clés: patrimoine minier; patrimoine géologique; géoparcs; tourisme minier; géotourisme

\begin{abstract}
Visibility and promotion of mining heritage in some Spanish geoparks
The material and immaterial remains of mining activities have undergone a growing process of heritage valorization that has allowed sustaining relevant cultural initiatives, among them mining museums and mining parks. This paper examines mining heritage in the context of the UNESCO Geoparks. The objective is to heighten the visibility of the mining heritage by taking advantage of the Geoparks "brand" when integrating mining tourism activities in geotourism. The methodology centers primarily on a review of the literature and the consultation of information provided by the geoparks on tourism promotion. A theoretical review of actions in the Cabo de Gata-Nijar, Sierra Norte de Sevilla, Villuercas-Ibores-Jara and Central Catalonia geoparks reveals the importance of mining heritage.
\end{abstract}

Keywords: mining heritage; geological heritage; geoparks; mining tourism; geotourism

\title{
Sumario
}

1. Patrimonio minero y patrimonio geológico: recursos para el desarrollo

\section{Geoparques y geoturismo,} dos categorías en alza
3. Resultados: geoparques y visibilidad del patrimonio minero en España

4. Conclusión

Referencias bibliográficas

\section{Patrimonio minero y patrimonio geológico: recursos para el desarrollo}

Las reformulaciones teóricas y metodológicas en el marco de las ciencias sociales guían, en las últimas décadas, la continua puesta al día de planteamientos y enfoques a la hora de abordar temáticas de carácter multidisciplinario. Es lo que ocurre con el concepto de patrimonio, cuyo alcance se ha ampliado, al pasar de centrarse en el monumento (objeto concreto) a considerar el propio territorio (y sus paisajes), un «bien no renovable, esencial y limitado» (VVAA, 
2006) que puede y debe actuar como elemento estratégico (recurso), y más aún en áreas desfavorecidas, donde, con una gestión adecuada, puede convertirse en un «activo económico de primer orden».

Planteamos aquí la valoración del patrimonio ligado a las actividades extractivas, presente en muchas cuencas después de su cierre en la etapa postindustrial, que identificamos como patrimonio minero. Lo integran el conjunto de restos materiales e inmateriales heredados de la minería que se han desarrollado en el pasado o que se desarrollan en la actualidad y que conforman la memoria colectiva de una población determinada. Con una vertiente geológica vinculada a la riqueza del yacimiento (patrimonio geológico minero) y otra relacionada con los espacios productivos (cuenca minera) y los sociales (hábitat, servicios, etc.), se le reconoce el valor histórico como fuente de información de anteriores etapas, el valor material que conserva el patrimonio mueble e inmueble, el valor cultural y sentimental, el valor estético de la arquitectura industrial, el valor emocional relacionado con la trayectoria vital de los mineros y el valor tecnológico derivado del proceso extractivo (Álvarez, 2009: 29-30; Cañizares, 2011a: 2). Un patrimonio que, convenientemente valorizado, sustenta algunas iniciativas turísticas relevantes en nuestro entorno europeo (Mina de Wieliczka en Polonia, Ecomuseo de Le Creusot-Montceau-Les Mines en Francia, etc.) y que, en España, presenta sus mejores ejemplos con los parques y los museos mineros (Riotinto, Almadén, La Unión, MWNAS Andorra-Sierra de Arcos, etc.) (Cañizares, 2011b), asociados a tipologías de turismo minero, turismo de patrimonio minero o geominero, incluso una variedad de geoturismo, siguiendo el modelo anglosajón (Hose, 2017: 32). Más aún en entornos rurales desfavorecidos donde la conservación y la adaptación al uso turístico de este patrimonio ha dado resultados aceptables, aunque son muy numerosas las dificultades a las que se enfrenta (mantenimiento de instalaciones, inversiones, etc.), según han trabajado Valenzuela et al. (2008: 231 y s.) para El Bierzo, la Montaña Palentina, Guadix y las Cuencas Mineras de Teruel.

Conscientes de que aún queda mucho camino por recorrer en su protección, defensa y valorización como parte del patrimonio propiamente industrial (Palacios e Hidalgo, 2009: 172 y s.; Benito et al., 2016: 86) y de que España se sitúa por detrás de otros países en los que la sensibilización hacia su protección es mucho mayor, después de un dilatado período de progresiva atención se ha convertido, en la mayoría de las comunidades autónomas, en un apreciado recurso para el desarrollo, como demuestran numerosas actuaciones (Cañizares et al., 2016: 449), algunas de las cuales están relacionadas con la «reinvención» turística de los territorios mineros o la rehabilitación de instalaciones mineras abandonadas, al considerarse una oportunidad para recuperar un patrimonio que, sin un nuevo uso, estaría abocado a su irreversible deterioro (Cueto, 2016: 1013). Se logra con ello superar un período de ignorancia y desidia administrativa, así como otras dificultades económicas, legales y físicas (Pardo, 2010: 239 y s.), aunque continúa padeciendo restricciones de variada tipología (Llurdés, 2017: 152-156): conceptual, dada la visión tradicional del patrimonio y la dificultad de incorporar nuevas miradas; temporal, al tratarse de elementos 
bastante recientes; de mercado, por la dificultad de hacerse un hueco en el sector turístico y las modestas cifras de visitantes; económica, ya que el impacto real en la estructura monetaria de territorios desindustrializados no ha sido muy notorio; administrativa, por los elevados costes de revalorización, la falta de apoyo empresarial, la ausencia de turoperadores turísticos especializados y una cierta desconexión entre la oferta pública y la privada en la promoción, y paisajística, por las peculiaridades del paisaje minero y la necesidad de tenerlo en cuenta en los procesos de reconversión y recuperación territorial.

En este sentido, constatamos que el turismo minero está basado, fundamentalmente, en la riqueza patrimonial de las minas, aunque también se puede combinar con el de tipo empresarial o activo (Palacios e Hidalgo, 2009: 176). Se consolida muy lentamente y sigue siendo minoritario, si no se plantea dentro de estrategias de desarrollo más amplias en las que se integren distintos recursos territoriales. Esto ocurre en pocos casos, entre los cuales encontramos Riotinto (Huelva), el parque minero que más visitas recibe (94.464 en 2017), porque sus visitantes, especialmente extranjeros, entran en un circuito que combina lugares y recursos complementarios (García et al., 2013: 145 y s.).

Nuestro objetivo es favorecer la sensibilización hacia la riqueza patrimonial minera, materializada en elementos tangibles (edificaciones, castilletes, etc.) e intangibles (fiestas, cultura minera, etc.), en estrecha relación con la riqueza geológica de la que forma parte, y hacerlo, preferentemente, en aquellos territorios que han adquirido la categoría de geoparques, auspiciados por la Unesco. Áreas con un patrimonio geológico de importancia internacional, donde se desarrollan estrategias para la gestión holística del patrimonio, la promoción y el desarrollo sostenible, con enfoques innovadores, integrados y respetuosos con las tradiciones y los deseos locales (GGN, 2014: 1), un concepto relativamente nuevo que se abre paso con fuerza e identifica una nueva forma de proteger el territorio y su diversidad biológica, aportando una «marca» con cierta potencia para atraer la atención de un público que busca una experiencia turística diferente, lo cual puede favorecer la visibilidad y el aprovechamiento socioeconómico del patrimonio minero. En algunos casos, de hecho, este ha servido de criterio fundamental para la declaración de algunos geoparques en el mundo, como Cooper Coast en Irlanda; Terra Vita en Alemania; Idrija en Eslovenia (figura 1); los italianos Rocca di Cerere en Sicilia, el Parco Geominerario de Cerdeña y el Parco de la Colline Matallifere en Toscana, o el de la Comarca Minera Hidalgo en México (Marchán y Sánchez, 2013: 84).

Partiendo de la obviedad de que entre el patrimonio minero y el geológico existen vínculos innegables y reconocidos por el IGME (Instituto Geológico y Minero de España), este último está formado por el conjunto de recursos naturales geológicos de valor científico, cultural y/o educativo, ya sean formaciones y estructuras, formas del terreno, minerales, rocas, meteoritos, fósiles, suelos y otras manifestaciones que permiten conocer, estudiar e interpretar aspectos diversos de la Tierra: el origen y la evolución; los procesos que la han modelado; los climas y los paisajes del pasado y del presente, y el origen y la evolución de la vida, según expone la Ley 42/2007 del patrimonio natural y de 
Figura 1. Sendero y canalizaciones hidráulicas mineras en el geoparque de Idrija (Eslovenia)

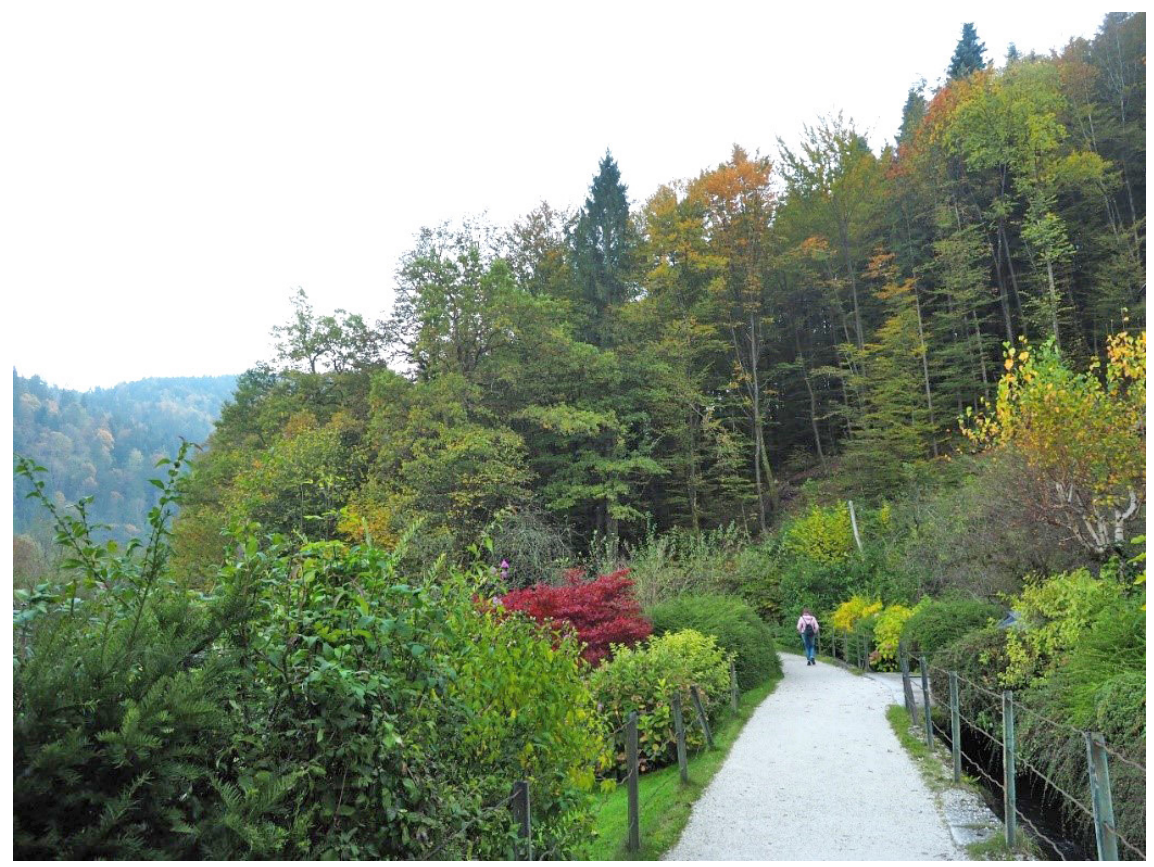

Fuente: elaboración propia (octubre de 2016).

la biodiversidad. Su máxima representación son los lugares de interés geológico (LIG), áreas de especial relevancia a las que se añaden las colecciones de fósiles y minerales. Su conservación es necesaria y su valorización se vincula con diversas iniciativas de patrimonialización institucional, como las que se incluyen en la Lista del Patrimonio Mundial Unesco, con más de 200 zonas catalogadas.

La gran riqueza geológica existente en España se concreta en más de 3.000 LIG incluidos en el inventario del IGME, 42 de ellos de relevancia internacional, según el Proyecto Geosites (Carcavilla y Palacio, 2010; Farsani et al., 2011: 68 y s.). Como en el caso del patrimonio minero, el geológico, adecuadamente gestionado, puede llegar a constituir una pieza fundamental del bienestar social y económico de su entorno, además de contribuir eficazmente al desarrollo sostenible de los ambientes rurales donde generalmente se localiza, según expone la Declaración de Girona sobre la Protección del Patrimonio Geológico (<http://www.igme.es/patrimonio/links/declaracionGirona.htm>). No obstante, su reconocimiento es también limitado y no se encuentra exento de las mismas dificultades relacionadas con la falta de sensibilización hacia su conservación y protección por parte de administraciones y sociedad, o los problemas de financiación para generar centros de interpretación y/o museos. Aun así, en las dos últimas décadas han proliferado redes internacionales para 
su conservación, lo que ha favorecido su reconocimiento (Palacio, 2013: 24), prueba de lo cual son los 140 geoparques mundiales Unesco localizados en 37 países.

Consideramos por ello que aprovechar esa sinergia de recursos ${ }^{1}$ no solo incentivará las visitas, sino que también dará a conocer mucho mejor y con mayor rigor la geodiversidad de determinadas áreas, adoptando «un marco - patrimonial- más amplio de lo que ha sido habitualmente» (Llurdés, 2016: 615). Son muchos los valores compartidos: de carácter intrínseco, por expresar la relación entre el ser humano y la naturaleza; culturales, por su independencia con un entorno social determinado; estéticos, en su relación con la contemplación del paisaje; económicos, por el valor que les atribuye la sociedad; funcionales, por cuanto tienen una carácter utilitario para el hombre; científicos, en relación con la información que aportan, y educativos, por su carácter pedagógico (Leite et al., 2015: 51 y s.). Recientemente, patrimonio minero y patrimonio geológico han sido considerados «en cierto modo otro tipo de minería, ya que la minería no deja de ser la utilización de los georrecursos para cualquier finalidad, ya sea científica, didáctica o turística» (Puig et al., 2016: 405).

En este planteamiento inicial coincidimos plenamente con Llurdés (2017: 155), al afirmar que «se trataría de cambiar una lectura exclusivamente cultural del patrimonio, visto de una forma más bien aislada, por otra propiamente más geográfica en la que el patrimonio (minero) debe formar parte de una estrategia de desarrollo más global, sin que quede desligado del contexto territorial en el que está inscrito", es decir, contemplar el paisaje minero con otra mirada que «obligase» a los territorios a realizar un proceso de reinvención y de diferenciación, que aquí proponemos aprovechando la figura de los geoparques.

\section{Geoparques y geoturismo, dos categorías en alza}

Abordamos la figura de los geoparques en el marco de las redes a distintas escalas y las posibilidades ofrecidas por el geoturismo desde un enfoque integral.

\subsection{Redes de geoparques a diferentes escalas}

La concepción de los geoparques, identificando territorios que incluyen un patrimonio geológico particular y una estrategia de desarrollo territorial sostenible, surge en Europa en el año 2000, cuando, dentro del programa de desarrollo rural LEADER, se unen cuatro territorios: la Réserve Géologique de Haute-Provence (Francia), el Bosque Petrificado de Lesvos (Grecia), el Geoparque Vulcaneifel (Alemania) y el Maestrazgo turolense (España), para firmar la Carta de la Red Europea de Geoparques, con el fin de promover la etiqueta Geoparques Europeos como una marca de alta calidad en geoturismo. Se crea, entonces, la Red Europea de Geoparques (EGN, European Geoparks

1. Los congresos internacionales GEOTUR y la Red Ibérica de Espacios Geomineros unen ambas temáticas. 
Network), que en 2018 (junio), convertida en «la iniciativa más importante para la conservación y promoción del patrimonio geológico en la Unión Europea» (<http://www.europeangeoparks.org/>), incluye 73 territorios catalogados como tales en 21 países y tiene como objetivo apoyar a sus miembros en el desarrollo territorial sostenible.

Cada geoparque es responsable de un plan de gestión y acción que describa su funcionamiento, así como de actividades en relación con la identificación y la evaluación de sitios del patrimonio terrestre, la validación de elementos del patrimonio natural y cultural, la protección del geositio y la geoconservación, las infraestructuras y las actividades de interpretación del patrimonio y de geoturismo, las herramientas de educación ambiental, la promoción, el apoyo a las empresas locales, la supervisión y las relaciones internacionales.

Un año después, en 2001, la firma de un acuerdo con la Unesco supuso el germen de la Red Global de Geoparques (GGN, Global Geoparks Network), que comienza a funcionar en 2004 como una organización legal sin fines de lucro, en la que los miembros se comprometen a trabajar juntos, intercambiar ideas de mejores prácticas y participar en proyectos comunes para elevar los estándares de calidad de productos y prácticas. Ratificada mediante la Declaración en la Sexta Conferencia Internacional Unesco, dentro del Programa Internacional de Ciencias de la Tierra, actualmente se gestiona en colaboración con la Global Geoparks Network International Association, creada en 2014. Formada, inicialmente, por 17 parques europeos y 2 chinos, hoy agrupa 140 geoparques mundiales Unesco, cuya labor es crucial en colaboración y cooperación.

En España, la red mundial está representada por el Foro Español de Geoparques, donde se integran, en el momento actual, 12 territorios caracterizados por un patrimonio geológico singular, una estrategia de desarrollo propia, límites definidos y una superficie suficiente para generar su propio desarrollo económico contemplando la calidad de vida de sus habitantes (<http://geoparques.eu/>).

\subsection{Geoturismo y promoción del patrimonio en el territorio}

Aunque un geoparque debe demostrar que posee un patrimonio geológico de interés internacional, el propósito de esta figura, según la Unesco, no solo es conservar o dar a conocer la geología como tal, sino también explorar y desarrollar los posibles vínculos existentes entre la gea y los demás patrimonios (natural, cultural, intangible, etc.) a través del turismo o del geoturismo (FernándezMartínez et al., 2014: 62). Una tipología específica que ofrece, básicamente, una oferta centrada en recursos geológicos asociados a determinados tipos de paisajes (volcánicos, kársticos, etc.), pudiendo así promocionar el patrimonio inserto en el territorio, lo que en geografía denominamos patrimonio territorial, para algunos llamado geopatrimonio (geoheritage).

Hace una década, Voth (2008: 11) afirmaba que, en el debate sobre los geoparques, había que afrontar el reto de definir las posibilidades de integrar 
el patrimonio cultural geominero en los equipamientos y en las actividades, así como aclarar las relaciones entre los diversos tipos de parques culturales o geomineros y el propio concepto de geoparque. Hoy, la utilización del patrimonio geológico, la identidad y el sentido de pertenencia a favor de proyectos educativos, de la geoconservación, la divulgación y el desarrollo local son algunas de sus principales fortalezas (Sánchez et al., 2013: 47), aunque todavía queda camino por recorrer en su interpretación y promoción.

El concepto de geoturismo busca asiento multidisciplinario y, junto con el de geoparque, guarda "una estrecha relación con el de geodiversidad» (Llurdés, 2016: 614). La Declaración de Arouca (2011) lo vincula con el turismo que sustenta e incrementa la identidad de un territorio, considerando su geología, ambiente, cultura, valores estéticos, patrimonio y el bienestar de sus residentes. Es decir, que trata de explorar la geodiversidad dentro de un esquema de desarrollo sostenible donde prestadores de servicios y turistas comprenden y se comprometen con la conservación de los sitios con valor geológico y minero (Fernández et al., 2015: 22), por lo que incluiría perfectamente al turismo minero. Convertido en un instrumento valioso para lo que se ha denominado geoconservación (Carcavilla et al., 2011: 82), responde a un proceso global emergente (Dowling y Newsome, 2006), pues avanza hacia el marketing y el uso turístico del potencial paisajístico y de las peculiaridades regionales relacionadas con la historia de la Tierra (Voth, 2008: 4). Ello sucede en algunas cuevas visitables (Geoparque de las Subbéticas en España), en la contemplación de las huellas de dinosaurio o icnitas (Maestrazgo en España), en gargantas y cañones (Geoparque Luberon en Francia), cascadas (Fforest Fawr Geopark en Gales) o procesos glaciares (Parque Natural de Adamello-Brenta en Italia), ejemplos que permiten sustentar la idea de que el geoturismo permite analizar las interacciones entre paisaje y turismo (Stoffelen y Vanneste, 2015: 544).

Incluso, en relación con las áreas mineras, ofrece la posibilidad de relacionar cultura y ciencia desde un enfoque amplio, como sucede en las minas australianas de Queenstown en Tasmania y de Yallourn en Victoria (Walliss y Kok, 2014: 33 y s.). En este sentido, consideramos que el patrimonio minero, convenientemente valorizado y convertido en producto al servicio del turismo, presenta un encaje complementario en esta tipología turística, pues comparte intereses en relación con la interpretación del territorio. Según Rybár y Strba (2016: 2 y s.), la diferencia entre geoturismo y turismo minero radica en la forma en que se presenta el producto a los turistas y en aquello que incluye su oferta, siendo la segunda tipología la más específica. Además, en un contexto tan competitivo como el actual, no debería obviarse el aprovechamiento del «turismo de proximidad» (Llurdés et al., 2016: 55 y s.) como una forma transversal de turismo, compatible con otras y relacionada con la revalorización del patrimonio local por la propia población, sobre todo porque en España lo más probable es que muy poca gente conozca con detalle los impactos que en el entorno de un lugar se han derivado de la antigua actividad de una fábrica o una mina. 


\section{Resultados: geoparques y visibilidad del patrimonio minero en España}

Según lo analizado anteriormente, a los geoparques se les presupone un impacto directo en el territorio, al influir en el bienestar de sus habitantes, ya que el objetivo final es permitirles reapropiarse de los valores del patrimonio del territorio y participar activamente en su revitalización cultural ( $<$ http://www. europeangeoparks.org/>), para lo que se requiere cooperación entre población, científicos, industrias turísticas, municipalidades, gobiernos y otras partes interesadas (<http://www.globalgeopark.org/>), especialmente entre la población local y los visitantes, que, según la Declaración de Arouca, deben involucrarse y no solo limitarse al simple papel de espectadores, «contribuyendo a construir una identidad local, promoviendo los valores auténticos y únicos del territorio», en favor de la «integridad medioambiental, justicia social y desarrollo económico sostenible». Fomentan, entonces, el sentido del lugar (Sánchez, 2011: 48) $y$, en este contexto, analizamos las posibilidades de mejorar la visibilidad del patrimonio minero inserto en algunos geoparques.

\subsection{Patrimonio minero, geoparques y turismo en España}

Conscientes de que estas iniciativas pueden despertar la conciencia social sobre la importancia del patrimonio cultural (Voth, 2008: 11), aprovechar las singularidades de cada territorio para su promoción, potenciando la sinergia de recursos, puede ser determinante en su dinamización. Así, entendemos la conexión entre el patrimonio minero y el patrimonio geológico viable desde diferentes puntos de vista:

- Como parte de un patrimonio común, "patrimonio de la Tierra» o "geopatrimonio" desde los enfoques más naturalistas y/o ingenieriles, o bien "patrimonio territorial» desde la óptica geográfica, que es necesario conservar y proteger para las generaciones.

- Como elementos (recursos) complementarios por aunar en una misma experiencia aspectos naturales (geológicos) y aspectos culturales (mineros) que, valorizados, aportan información de cómo el medio ha ofrecido posibilidades al hombre para sobrevivir en él.

- Para fortalecer la identidad local, fomentando el intercambio cultural, así como el desarrollo territorial sostenible.

En España existen 13 geoparques (figura 2), incluyendo también el Maestrazgo, aunque, en el momento actual, no goza de la categoría Geoparque Mundial Unesco, y en todos se cumplen tres principios fundamentales según el IGME:

1. La existencia de un patrimonio geológico que sirve de protagonista y eje conductor.

2. La puesta en marcha de iniciativas de geoconservación y divulgación.

3. La promoción del desarrollo socioeconómico y cultural a escala local. 
Figura 2. Localización de los geoparques en España (2018)

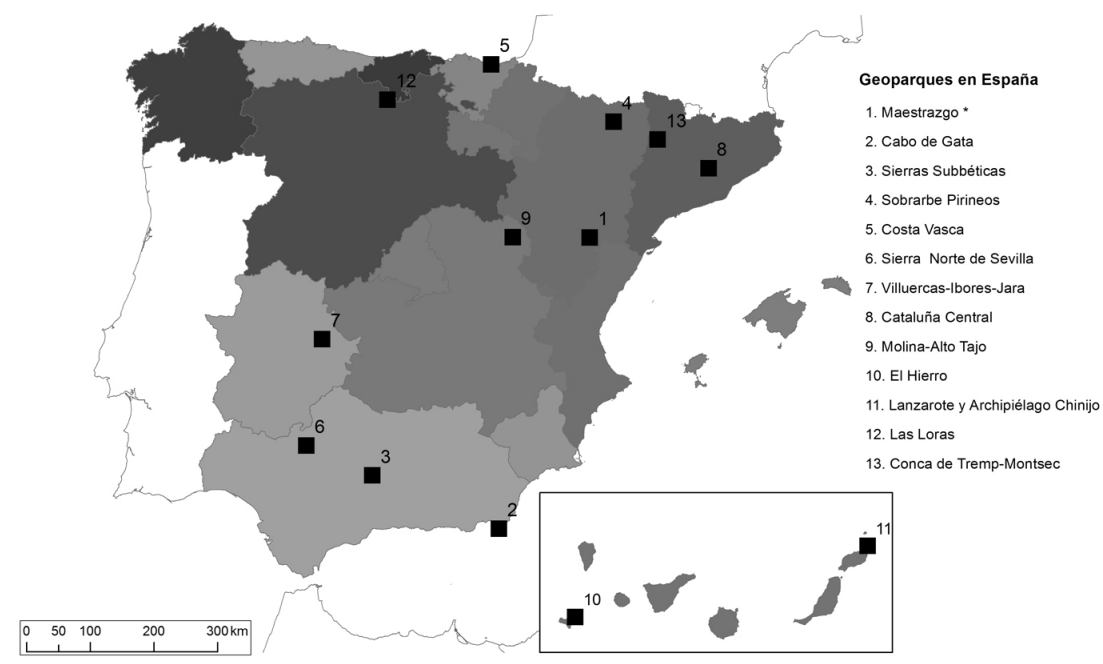

* El Maestrazgo no forma parte, actualmente, de los geoparques Unesco.

Fuente: elaboración propia.

Identificamos a continuación (tabla 1) las principales iniciativas de valorización del patrimonio minero que existen en algunos de ellos (resaltados en negrita). Frecuentemente identificadas como geositios mineros (naturales y/o antrópicos), estas iniciativas las encontramos prácticamente en todos los geoparques, aunque solo en algunos están convenientemente valorizadas, incluso en casos concretos mantienen actividad productiva (salinas), por lo que seleccionaremos a continuación aquellas que ya conformen un producto turístico de calidad y sustenten una oferta consolidada. Responden, mayoritariamente, a la rehabilitación de elementos mineros inmuebles (instalaciones, minas subterráneas y a cielo abierto, poblados, etc.), bienes muebles (maquinaria, herramientas, documentación, etc.) y los elementos vinculados con el patrimonio inmaterial derivado de usos y costumbres, es decir, la «cultura minera» y la memoria del trabajo que perdura a través de las fiestas y del folclore local o la gastronomía. Esta última constituye por sí misma un recurso turístico en algunos casos como el de Cataluña Central, aunque en España su difusión no es práctica habitual (Llurdés, 2016: 621-622).

\subsection{Algunas iniciativas destacadas}

Los geositios mineros insertos en algunos geoparques de España contienen valores naturales, históricos, tecnológicos, económicos, etc. que, en algunos casos, se han sometido a procesos de patrimonialización a partir del recono- 
Visibilidad y promoción del patrimonio minero en algunos geoparques españoles María del Carmen Cañizares

Tabla 1. Geoparques en España (2018)

\begin{tabular}{|c|c|c|c|c|}
\hline Geoparques & Provincia & Año & Valores geológicos destacados & $\begin{array}{l}\text { Principales iniciativas } \\
\text { de turismo minero }\end{array}$ \\
\hline Maestrazgo* & Teruel & 2004 & $\begin{array}{l}\text { Parque Geológico de Aliaga, Gruta de Cristal, } \\
\text { icnitas, estructuras tectónicas, series } \\
\text { paleontológicas, elementos geomorfológicos. }\end{array}$ & $\begin{array}{l}\text { Museo Minero de Escucha. } \\
\text { Parque Minero MWNAS. }\end{array}$ \\
\hline Cabo de Gata-Nijar & Almería & 2006 & $\begin{array}{l}\text { Sierra volcánica del cabo y la llanura litoral } \\
\text { de la bahía de Almería, paisajes litorales. }\end{array}$ & $\begin{array}{l}\text { Centro geoturístico La Casa } \\
\text { de los Volcanes y salinas. }\end{array}$ \\
\hline Sierras Subbéticas & Córdoba & 2006 & $\begin{array}{l}\text { Morfologías kársticas, series estratigráficas } \\
\text { del jurásico. }\end{array}$ & - \\
\hline Sobrarbe-Pirineos & Huesca & 2006 & $\begin{array}{l}\text { Elementos tectónicos y geomorfológicos, } \\
\text { yacimientos paleontológicos, paisajes de montaña. }\end{array}$ & - \\
\hline Costa Vasca & Guipúzcoa & 2010 & $\begin{array}{l}\text { Secciones estratigráficas, Flysch de Zumaya, } \\
\text { acantilados, karst, paisajes litorales. }\end{array}$ & - \\
\hline Sierra Norte de Sevilla & Sevilla & 2011 & $\begin{array}{l}\text { Complejo kárstico, yacimiento paleontológico, } \\
\text { huellas de medusas, anfibolitas. }\end{array}$ & Mina del Cerro del Hierro. \\
\hline Villuercas-Ibores-Jara & Cáceres & 2011 & $\begin{array}{l}\text { Elementos geomorfológicos (sierras y valles } \\
\text { apalachenses) y yacimientos paleontológicos, fósiles. }\end{array}$ & $\begin{array}{l}\text { Mina La Constanza y Museo } \\
\text { Geominero de Logrosán. }\end{array}$ \\
\hline Cataluña Central & Barcelona & 2012 & $\begin{array}{l}\text { Elementos geomorfológicos, yacimientos minerales, } \\
\text { cuevas, yacimientos minerales (potasas). }\end{array}$ & $\begin{array}{l}\text { Parque Cultural de la } \\
\text { Montaña de Sal de Cardona. }\end{array}$ \\
\hline Molina-Alto Tajo & Guadalajara & 2014 & $\begin{array}{l}\text { Sierras y valles fluviales (río Tajo), bosques, } \\
\text { yacimientos arqueológicos. }\end{array}$ & $\begin{array}{l}\text { Salinas de Saelices. } \\
\text { Mina de La Estrella. }\end{array}$ \\
\hline El Hierro & $\begin{array}{l}\text { Santa Cruz } \\
\text { de Tenerife }\end{array}$ & 2014 & $\begin{array}{l}\text { Paisaje volcánico, dorsales, lavas petrificadas, } \\
\text { fondos marinos. }\end{array}$ & - \\
\hline $\begin{array}{l}\text { Lanzarote y } \\
\text { Archipiélago Chinijo }\end{array}$ & Las Palmas & 2015 & $\begin{array}{l}\text { Paisajes y ecosistemas volcánicos } \\
\text { (campos de lavas, conos, cráteres, etc.). }\end{array}$ & Salinas de Janubio. \\
\hline Las Loras & $\begin{array}{l}\text { Palencia } \\
\text { y Burgos }\end{array}$ & 2017 & $\begin{array}{l}\text { Elementos geomorfológicos (valles, cañones } \\
\text { fluviales, etc.), yacimientos paleontológicos } \\
\text { y minerales (petróleo). }\end{array}$ & $\begin{array}{l}\text { Museo del Petróleo. } \\
\text { Centro de Interpretación } \\
\text { de la Minería. }\end{array}$ \\
\hline $\begin{array}{l}\text { Conca de } \\
\text { Tremp-Montsec }\end{array}$ & Lleida & 2018 & $\begin{array}{l}\text { Estructuras geológicas (perfil sísmico ECORS } \\
\text { Pirineos), yacimientos paleontológicos (dinosaurios), } \\
\text { lagos. }\end{array}$ & Museo de Gerri de la Sal. \\
\hline
\end{tabular}

* El Maestrazgo no se encuentra integrado dentro de los geoparques mundiales Unesco.

Fuente: Carcavilla y García (2014: 6), Foro Español de Geoparques (enero de 2018) y elaboración propia.

cimiento institucional (inventarios, catálogos) de sus bienes con iniciativas diversas (museos, centros de interpretación, etc.), junto con una progresiva valoración por parte de la población local, que ha contribuido a su consideración como parte fundamental de la identidad territorial, algo complicado en los territorios mineros. Destacamos, a continuación, cuatro iniciativas que pueden servir de ejemplo para futuras actuaciones e integrarse en los mecanismos de restauración, conservación y explotación del patrimonio para que el territorio vuelva a generar riqueza desde una visión poco restrictiva, en la que 
el patrimonio minero va más allá de lo que es una mina y los elementos que han hecho posible la actividad extractiva, para avanzar hacia los paisajes mineros (Llurdés, 2017: 158-160).

\subsubsection{Geoparque del Cabo de Gata-Nijar}

Con una superficie de $352 \mathrm{~km}^{2}$ (más $120 \mathrm{~km}^{2}$ de zona protegida marina), se extiende por los municipios andaluces de Almería, Níjar y Carboneras, en el extremo suroriental de la península Ibérica. Se trata de una de las franjas costeras más peculiares, ejemplo único de la estepa mediterránea, en la que habitan especies de flora y fauna realmente singulares $(<\mathrm{http}: / / \mathrm{www}$.juntadeandalucia. es/medioambiente/>). Su fachada litoral volcánica, con pequeñas calas y grandes playas, así como su patrimonio etnográfico, fruto de la interacción del hombre con un medio hostil, son sus señas de identidad, a las que unimos un rico patrimonio derivado de las explotaciones de oro. Se organiza en torno a dos unidades geológicas que configuran paisajes totalmente opuestos: la Sierra de Cabo de Gata, complejo volcánico que se formó hace 15-16 millones de años, y la Bahía de Almería, que presenta el registro geológico de los últimos 200.000 años del Mediterráneo, donde encontramos uno de los mejores ejemplos de sistemas activos de albufera adaptada por el hombre como explotación salinera, humedal RAMSAR y refugio para la avifauna acuática (flamencos), que puede ser visitada.

Un territorio ocupado por fenicios, romanos y árabes que dejaron su impronta en elementos como las torres y las fortalezas costeras, la cultura del agua (aljibes, tanques, pozos, etc.) y del viento (molinos y norias), donde las actividades pesqueras y la minería, desde finales del siglo XIX, han sido relevantes, junto con el turismo, más reciente. Entre las experiencias de geoturismo más significativas, ofrece cuatro itinerarios de georrutas submarinas, una georruta nocturna (Arrecife de las Sirenas) y una ruta geoturística minera (Valle de Rodalquilar). Con esta última vinculamos el rico patrimonio minero relacionado con las explotaciones de oro en Rodalquilar y Aguamarga, activas desde 1883 hasta 1990, cuando se rehabilita la antigua Casa de Fundición para crear el centro geoturístico ecomuseo La Casa de los Volcanes (figura 3), un año después de la declaración de geoparque.

Abierto en octubre de 2007 y después de haber superado algunos problemas de gestión, ha sido visitado por más de 110.000 personas (tabla 2) y agrupa cuatro grandes áreas expositivas: Red Mundial y Europea de Geoparques; geodiversidad de Andalucía; ambientes volcánicos, arrecifes de la bahía y cuaternarios de Cabo de Gata, y la Mina de Historias sobre el patrimonio minero. En su entorno encontramos, también, numerosos elementos minero-metalúrgicos (Hernández Ortíz, 2018: 40 y s.), las plantas Denver y Dorr, los lavaderos de mineral, instalaciones auxiliares, pozos de extracción (pozos de Teresa, mina El Triunfo, etc.), complejos mineros (Las Niñas, Ronda y Resto, Consulta, etc.) y canteras que conforman un paisaje minero muy singular, aunque en un estado de conservación precario. 
Figura 3. Lavaderos de mineral y La Casa de los Volcanes

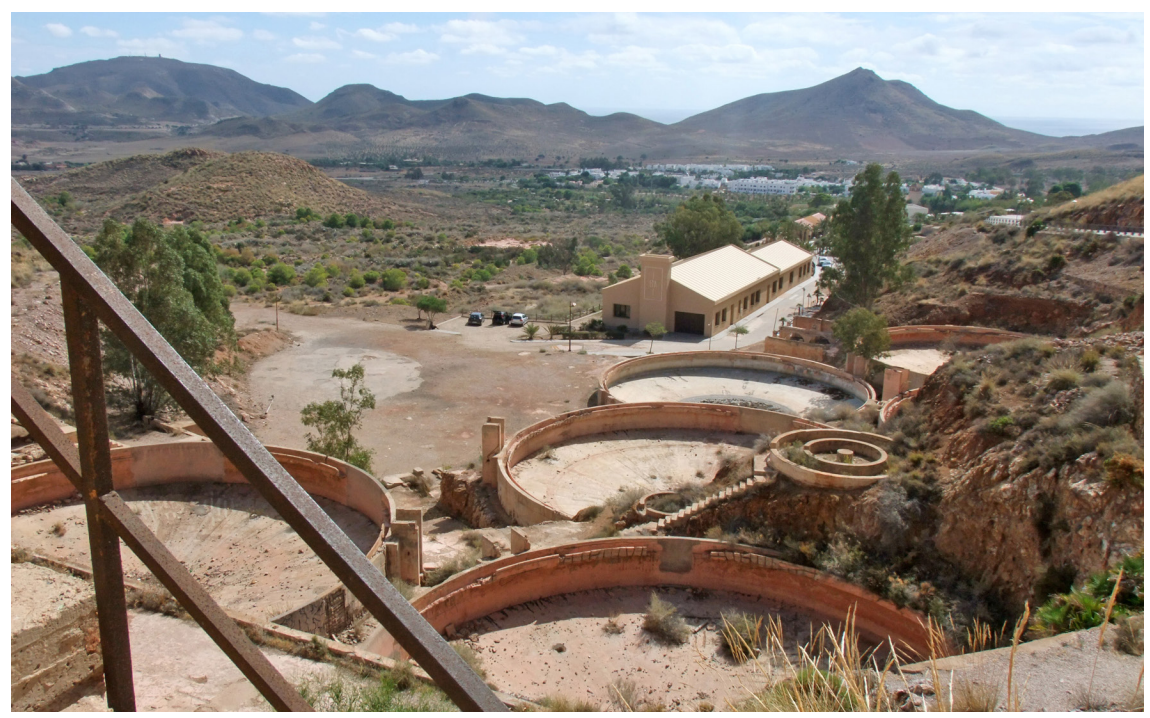

Fuente: elaboración propia (diciembre de 2014).

Tabla 2. Número de visitantes al ecomuseo La Casa de los Volcanes (2007-2017)

\begin{tabular}{lc}
\hline Años & Visitantes \\
\hline 2007 & 2.936 \\
2008 & 16.869 \\
2009 & 16.540 \\
2010 & 12.978 \\
2011 & 17.171 \\
2012 & 7.445 \\
2013 & 3.811 \\
2014 & 5.492 \\
2015 & 9.314 \\
2016 & 7.999 \\
2017 & 8.335 \\
\hline
\end{tabular}

Fuente: Ecomuseo La Casa de los Volcanes (octubre de 2018).

\subsubsection{Geoparque Sierra Norte de Sevilla}

Con una extensión de $1.774 \mathrm{~km}^{2}$, se sitúa en el noroeste de la provincia andaluza de Sevilla y abarca los municipios de Alanís, Almadén de la Plata, Cazalla de la Sierra, Constantina, Guadalcanal, Las Navas de la Concepción, El Pedroso, La Puebla de los Infantes, El Real de la Jara y San Nicolás del Puerto. Geológicamente presenta una gran variedad, debido a la diversidad en la naturaleza 
Figura 4. Cerro del Hierro

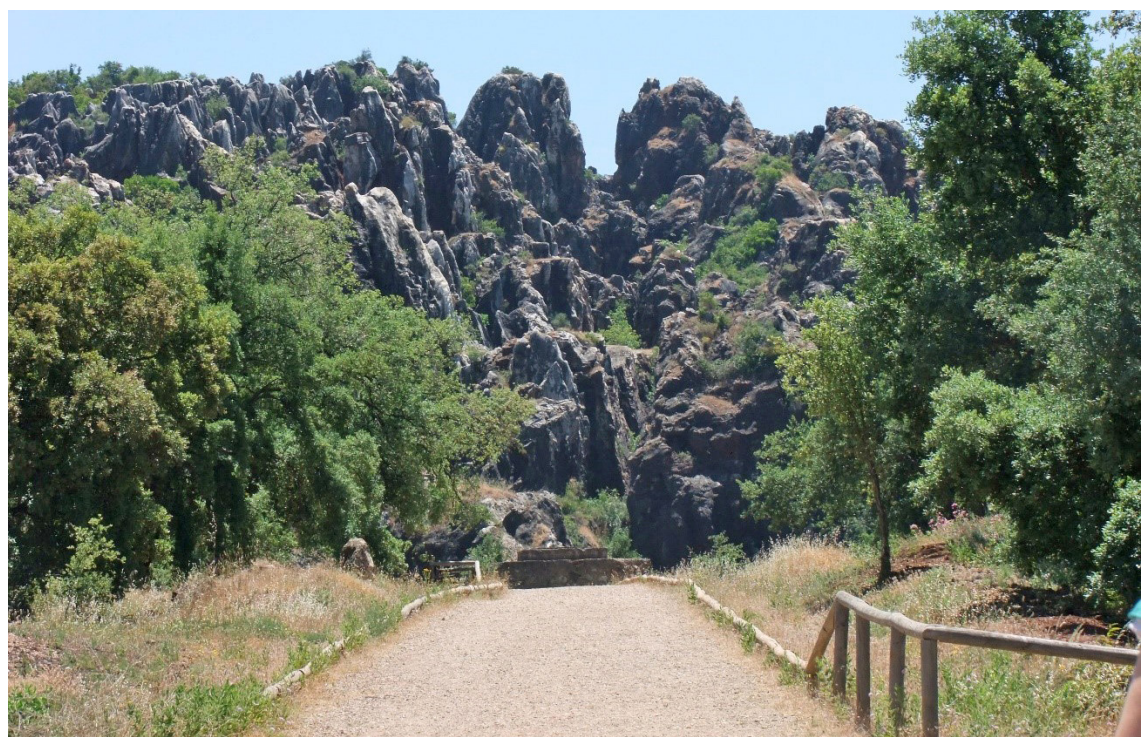

Fuente: elaboración propia (junio de 2015).

de las rocas (sedimentarias, metamórficas e ígneas), su edad (entre $1.000 \mathrm{y}$ 250 millones de años) y su composición, como demuestran las más de cien minas e indicios mineros antiguos que reflejan una historia casi continua de unos 700 millones de años, concretados en 39 geositios. Las formas del relieve son resultado de la disposición espacial producida por las orogenias hercínica y alpina, así como la erosión diferencial, que generan un paisaje de sierras en el que se alternan alineaciones de montañas abruptas, valles estrechos y profundos, además de zonas de planicies suaves y valles amplios, con múltiples elementos geomorfológicos (manantiales, cascadas, karst, hoyas, cuevas, cañones, berrocales, etc.). Sobresalen las dehesas, los pastizales arbolados, las formaciones boscosas de encinas, los alcornoques y los robles, los olivares, los castañares y los bosques de ribera, manifestando una elevada biodiversidad, tanto en flora como en fauna. Se encuentra, además, atravesado por el Camino Mozárabe a Santiago (extremo occidental) y el Camino Oriental de la Frontera (parte norte), a lo que se une su riqueza cultural y gastronómica derivada de las actividades rurales (Geoparque Villuercas-Ibores-Jara, 2018: 28 y s.).

La oferta geoturística se centra en actividades de barranquismo (Almadén de la Plata) y rutas con orientación geominera, como la del Laberinto de Piedra en el Cerro del Hierro (figura 4) y la de la Mina de la Lima. Desde el inicio de la edad de los metales, se explotaron minas de cobre y los romanos extrajeron mármol de varios cerros para uso constructivo y ornamental, momento a partir del cual también existen evidencias de la explotación del hierro, que se inten- 
Tabla 3. Número de visitantes en el Cerro del Hierro (2009-2017)

\begin{tabular}{lc}
\hline Años & Visitantes \\
\hline 2009 & $2.265^{\star}$ \\
2010 & 3.839 \\
2011 & 5.481 \\
2012 & 4.035 \\
2013 & 4.738 \\
2014 & 2.968 \\
2015 & $1.839^{\star \star}$ \\
2016 & 6.923 \\
2017 & 4.374 \\
\hline
\end{tabular}

* Sin datos de agosto a diciembre.

** Sin datos de diciembre.

Fuente: Parque Natural Sierra Norte de Sevilla (octubre de 2018). Información recogida en el punto de información Cerro del Hierro.

sificó en los siglos XIx y xx. Destacan los lugares ligados a la minería histórica, como la Necrópolis de La Traviesa, las Canteras Romanas de Los Covachos y de la Loma de Los Castillejos, la Mina del Cerro del Hierro o la Fundición de El Pedroso (<http://www.juntadeandalucia.es/>).

Precisamente, la Mina del Cerro del Hierro, monumento natural de Andalucía localizado entre San Nicolás del Puerto y Constantina, es uno de los mejores ejemplos para contemplar, en exterior y de manera conjunta, patrimonio geológico y minero, pues es resultado de los procesos de extracción, transformación y transporte de hierro hasta el puerto de Sevilla, desde 1895 hasta la década de 1980. Su espectacularidad radica en las formaciones kársticas (paleokars) bajo las que se sitúa la mina, donde sobresalen lápices y agujas de las rocas de caliza aflorantes (figura 4).

Presentan gran interés, también, los restos de edificaciones (naves), el poblado minero, las viviendas de ingenieros (Casas de los Ingleses), la iglesia, la escuela y el economato, así como el ramal ferroviario (Sevilla-Mérida), parcialmente convertido en vía verde (<http://www.minasdesierramorena.es/ guia-de-campo/conjuntos-mineros/cerro-del-hierro/>). El número de visitantes está recogido por el punto de información Cerro del Hierro desde 2011, año en el que se integra en el geoparque, aunque el acceso es libre, por lo que los datos finales no contabilizan todas las visitas (tabla 3).

\subsubsection{Geoparque de Villuercas-Ibores-Jara}

Ubicado en el sureste de la provincia extremeña de Cáceres, con $2.554 \mathrm{~km}^{2}$, se extiende por 19 municipios y 8 pedanías de las comarcas de Las Villuercas, Los Ibores y La Jara. Conforma un macizo montañoso paleozoico de gran extensión, entre las cuencas del Tajo y del Guadiana, con grandes plegamientos que revelan la historia de la Tierra en sus últimos 700 millones de años, ejemplo de paisaje apalachense. Su registro fósil alberga los primeros animales en los 
fondos marinos y lugares de interés geológico relevantes, como los cristales de la Cueva de Castañar de Ibor, el desfiladero del Pedroso, los riscos de Las Villuercas o los yacimientos minerales. Se complementa con la flora y la fauna características del bosque mediterráneo y está atravesado por varios caminos históricos como el de Guadalupe. Son numerosas, también, las actividades geoturísticas promocionadas, como la ruta A Vista de Pájaro en vehículos $4 \times 4$; la subida al risco de la Villuerca (panorámica) y al nacimiento del río Almonte; la ruta geoastronómica Del Geoparque a las Estrellas; la ruta cinematográfica Geosabores de Película, con visita a una explotación ganadera, o un safari fotográfico en el que se visitan 16 geositios.

Respecto a la valorización del patrimonio minero, destacamos la mina La Constanza y el Museo Geominero de Logrosán. La primera es uno de sus 44 geositios y forma parte del proyecto Minas de Logrosán para la recuperación y puesta en valor del patrimonio minero de estaño (casiterita y fosfato fluorapatito), explotado desde tiempos prehistóricos hasta mediados del siglo xx (1946) para la fabricación de abonos. Visitada por más de 36.000 personas hasta 2017, hoy es la única mina de interior preparada para visitas turísticas en Extremadura (Asociación de Cuevas Turísticas Españolas). Abierta al público en 2012, un año después de la declaración de geoparque, alberga distintas edificaciones mineras: fábrica de abono, cocedero de piritas, fábrica de finos, almacenes, castillete minero y edificio de motores del Pozo Calle, galerías del Pozo María, donde se aprecia cómo se formó el yacimiento (fallas tectónicas, mineralización de los filones, brechas tectónicas y geodas), y permite acercarse a los restos de la actividad humana relacionada con la extracción minera (agujeros de barrena, herramientas, iluminación, entibados, pozo, chimeneas de aireación, etc.). El último tramo de galería se recorre en un pequeño tren minero que conduce al exterior por la bocamina. Esta iniciativa, aún modesta en número de visitantes (tabla 4), se complementa con el Museo Geominero de Logrosán, dedicado al geólogo Vicente Sos Baynat, que expone una colección de materiales de la minería del estaño y del fosfato y paleontológicos (fósiles). Pendientes de acondicionamiento se encuentran actualmente la galería del polvorín (museo) y la fábrica de finos (recreación del antiguo molino de mineral), así como algunas bocaminas, trincheras y escombreras de las minas de estaño del cerro de San Cristobal

Tabla 4. Número de visitantes a la mina La Constanza (2012-2017)

\begin{tabular}{lc}
\hline Años & Visitantes \\
\hline 2012 & 2.315 \\
2013 & 5.836 \\
2014 & 6.454 \\
2015 & 5.819 \\
2016 & 7.813 \\
2017 & 8.220 \\
\hline
\end{tabular}

Fuente: Minas de Logrosán (octubre de 2018). 
(Chicharro et al., 2011) y una antigua galería del yacimiento de casiterita y wolframita de la mina de El Serranillo.

\subsubsection{Geoparque de la Cataluña Central}

Situado en el interior de Cataluña, se extiende por $1.300 \mathrm{~km}^{2}$ e integra los municipios de Collbató (en la comarca del Baix Llobregat), los treinta municipios de la comarca del Bages y cinco más (Moià, Calders, l'Estany, Monistrol de Calders y Santa Maria d'Oló) de la comarca del Moianès, en la provincia de Barcelona. Un territorio que tiene su origen en el anterior Parque Geológico y Minero, que reconocía la importancia de la actividad minera en el Bages (Llurdés, 2016: 620), y que hoy presenta contrastes donde la geología y el patrimonio minero, así como la minería activa, configuran una buena parte del paisaje. Su riqueza geológica se relaciona con la elevación de los Pirineos y la progresiva desecación marina que tuvo lugar hace más de 36 millones de años, lo cual provocó la precipitación de una enorme cantidad de sales y creó una de las reservas de sal (potasa y halita) más importantes de Europa en la denominada cuenca potásica catalana. De ahí se derivan hoy 46 puntos de interés geológico y minero, especialmente formaciones rocosas y cuevas espectaculares (Cuevas del Toll, Cuevas del Salnitre, etc.), algunas adaptadas para la visita que, junto con pliegues, fallas y rocas, son el testimonio del registro geológico de los últimos 42 millones de años de la Tierra.

Los paisajes están también vinculados a las planicies de la comarca del Bages, principalmente, donde la vegetación natural mediterránea ha sido alterada por los cultivos de vid y olivo, de los que se desprende un rico patrimonio cultural (barracas y tinas de vino), a los que se unen pinares, encinas y robles, acebos, arces o serbales (<http://www.geoparc.cat/>). Su destacado patrimonio románico y algunos lugares de peregrinación como el monasterio de Montserrat, dentro del parque natural del mismo nombre, completan su atractivo. Entre las iniciativas de geoturismo destacan: la Ruta de la Piedra Seca, que incluye la visita a las tinas del Torrent del Flequer de Bleda; el Último Tramo del Camino Ignaciano (San Ignacio de Loyola), de 24 kilómetros entre Montserrat y Manresa; así como las actividades de enoturismo relacionadas con la visita a las bodegas de la Denominación de Origen Pla de Bages. En general, un territorio que, desde el punto de vista turístico, no se aparta de una oferta «tradicional» de turismo rural, patrimonio monumental, senderismo, historia, cultura, etc., y donde la gastronomía y el enoturismo, basados en productos de temporada y de proximidad y con una clara oferta de restaurantes y bodegas (incluidos en los Fogons Gastronòmics del Bages) ponen de relieve que existe, aunque incompleta, una relación ciertamente visible entre la geología y la gastronomía (Llurdés, 2016: 622-623).

Especial relevancia han tenido y tienen las actividades mineras, principalmente relacionadas con las sales (la halita en Cardona y la silvinita en Sallent, Súria y Balsareny); las rocas ornamentales (Castellbell i el Vilar y Sant Vicenç de Castellet), o las explotaciones de lignito (San Mateu del Bages y otros). Una iniciativa especialmente relevante es el Parque Cultural de la Montaña de 
Figura 5. Parque Cultural de la Montaña de Sal de Cardona

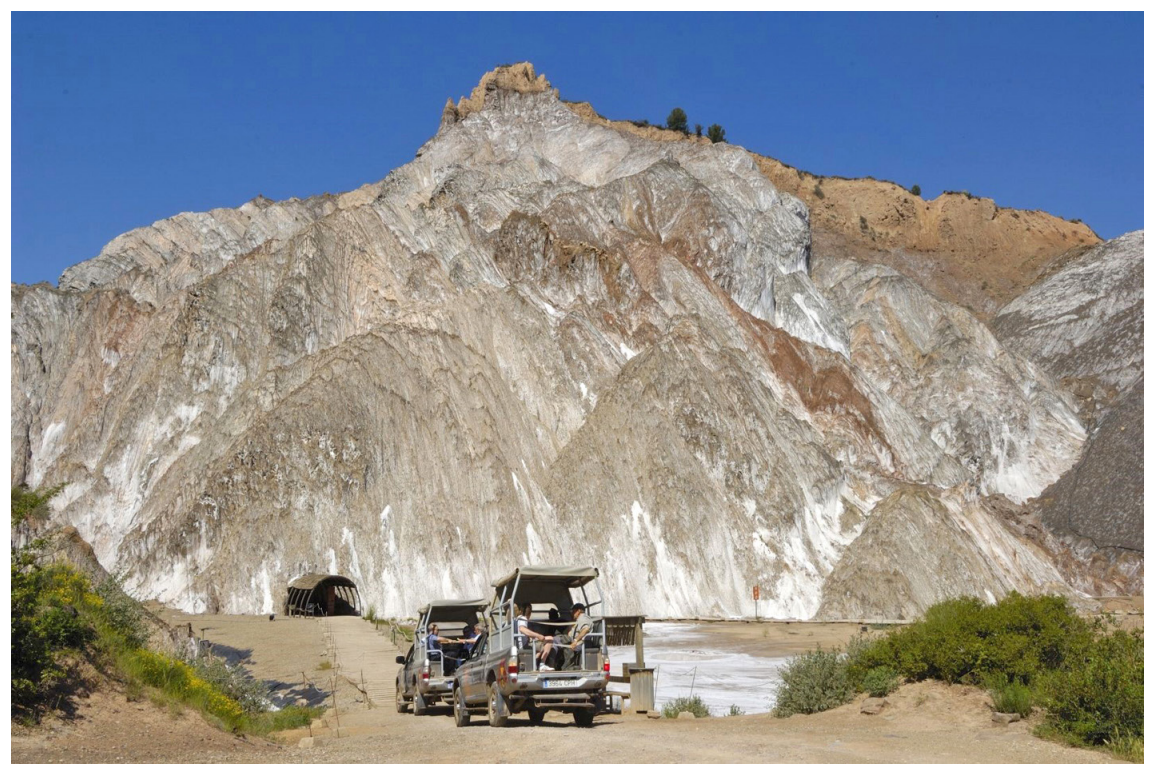

Fuente: VVAA, 2016.

Sal, en el límite del geoparque ${ }^{2}$, uno de los destinos de turismo minero y de geoturismo más atractivos de la península Ibérica, al permitir al visitante adentrarse a más de 80 metros de profundidad en una antigua explotación minera de sal potásica (Mina Nieves), activa desde 1929 hasta 1990. Una montaña de más de 120 metros de altitud (figura 5) que es la punta visible de un enorme diapiro de más de 2 kilómetros de profundidad.

Convertida en parque cultural desde 1997 e inserta en el Sistema Territorial mNACTEC ${ }^{3}$, busca divulgar la importancia de la sal, la excepcionalidad geológica del yacimiento y el aprovechamiento que el hombre ha hecho durante siglos, en un paisaje claramente alterado, pero, a la vez, dotado de gran singularidad, un paisaje "distintivo" en el que las propias escombreras destacan por su espectacularidad visual y ofrecen autenticidad (Llurdés, 2017: 162-163). Los datos (tabla 5) permiten aproximarnos a su relevancia, pues desde 1997 ha recibido anualmente un volumen importante de visitantes, a pesar de la crisis económica, que actualmente supera la cifra de 78.000 en 2017, de forma independiente al geoparque. Desde el punto de vista histórico, también encontramos, en su entorno inmediato, el castillo de Cardona (siglo XII), rehabilitado

2. Se encuentra fuera de los límites del geoparque, aunque se está gestionando su próxima ampliación.

3. Museu de la Ciència i de la Tècnica de Catalunya. Sistema que agrupa en red 27 museos y espacios patrimoniales de la industrialización de Cataluña (<http://sistema.mnactec.cat/es/>). 
Visibilidad y promoción del patrimonio minero en algunos geoparques españoles María del Carmen Cañizares

Tabla 5. Número de visitantes al Parque Cultural de la Montaña de Sal (1997-2017)

\begin{tabular}{cccc}
\hline Años & Visitantes & Años & Visitantes \\
\hline 1997 & 35.796 & 2008 & 67.300 \\
1998 & 70.391 & 2009 & 67.935 \\
1999 & 80.569 & 2010 & 66.390 \\
2000 & 66.992 & 2011 & 61.787 \\
2001 & 65.711 & 2012 & 56.779 \\
2002 & 70.799 & 2013 & 58.210 \\
2003 & 66.680 & 2014 & 67.253 \\
2004 & 71.196 & 2015 & 71.422 \\
2005 & 71.314 & 2016 & 76.414 \\
2006 & 71.995 & 2017 & 78.175 \\
2007 & 70.541 & & \\
\hline
\end{tabular}

Fuente: Fundació Cardona Històrica (octubre de 2018).

como parador nacional que alberga la colegiata románica de San Vicente. La oferta turística se completa con otras actuaciones, entre las que sobresalen el Museo de la Sal Josep Arnau, centrado en la artesanía local de la sal, o el Centro de Artesanía Art Sal (<http://cardonaturisme.cat/ $>$ ), y con una oferta gastronómica relevante (Llurdés, 2016: 614).

\section{Conclusión}

A través de cuatro iniciativas de valorización del patrimonio minero inserto en algunos geoparques españoles, correspondientes al ecomuseo La Casa de los Volcanes (Cabo de Gata-Níjar), el Cerro del Hierro (Sierra Norte de Sevilla), la mina La Constanza y el Museo Geominero de Logrosán (Villuercas-IboresJara) y el Parque Cultural de la Montaña de Sal de Cardona (Cataluña Central), hemos realizado una primera aproximación, fundamentalmente teórica, a las posibilidades que la categoría de geoparque Unesco ofrece de favorecer la visibilidad del patrimonio minero, en relación directa con el propiamente geológico, un tema aún muy poco trabajado en el ámbito académico español e internacional (Llurdés, 2016: 616-617). Además, conscientes de la dificultad de obtener información estadística desagregada, así como relativa a los agentes territoriales implicados, consideramos esta una primera aproximación a la temática que es susceptible de continuarse en el futuro, profundizando en aspectos concretos como los relacionados con la viabilidad socioeconómica.

Siguiendo los objetivos marcados por los geoparques en España, de «explorar, desarrollar y promover las relaciones entre su patrimonio geológico y todos los demás aspectos patrimoniales - ya sean naturales, culturales o intangiblespresentes en la zona» (<http://geoparques.eu/>), estas actuaciones responden a la valorización de geositios bajo presupuestos de sostenibilidad asociados al turismo (Ramsay, 2016; Geoparque Villuercas-Ibores-Jara, 2017, 2018) y surgen, en la mayor parte de los casos, después de la declaración de geoparque, aunque aún 
con cifras modestas de visitantes, excepto el de la Montaña de Sal, que conforma la oferta más sólida hasta el momento, potencialmente beneficiada, en un futuro próximo, por la «marca» geoparque. Ofrecen, como en otros lugares, oportunidades para la integración de aspectos científicos, tecnológicos y culturales, evitando algo frecuente, y es que «datos históricos, sociales, tecnológicos y económicos se presentan desvinculados de la caracterización del yacimiento» (Marchán y Sánchez, 2013: 81). En definitiva, una oportunidad para hacer las cosas mejor.

\section{Referencias bibliográficas}

Álvarez, Miguel Ángel (2009). «A propósito de la Carta del Bierzo». Revista Patrimonio Cultural de España, 0, 27-41.

Benito, Paz; Cañizares, M. ${ }^{a}$ Carmen y Pascual, Henar (2016). «Enfoques y actuaciones sobre el patrimonio industrial español y su importancia como recurso ante la crisis». En: Comité Español de la Unión Geográfica Internacional. Crisis, goblalización y desequilibrios sociales y territoriales en España. Madrid: IGN y Asociación de Geógrafos Españoles, 77-87.

Cañizares, M. ${ }^{a}$ Carmen (2011a). «Protección y defensa del patrimonio minero en España». Scripta Nova: Revista de Geografía y Ciencias Sociales, XV (361). Recuperado de <http://www.ub.edu/geocrit/sn/sn-361.htm>.

- (2011b). «Patrimonio, parques mineros y turismo en España». Cuadernos de Turismo, 27, 133-153.

Cañizares, M. a Carmen; Pascual, Henar y Benito, Paz (2016). «Buenas prácticas en la reutilización del patrimonio industrial como recurso para el desarrollo en España». En: García Marín, R. et al. (eds.). XV Coloquio Ibérico de Geografía: Retos y tendencias de la Geografia Ibérica. Murcia: Universidad de Murcia, AGE y APG, 443-451.

Carcavilla, Luis y García, Ángel (2014). Geoparques: Significado y funcionamiento. Madrid: IGME. Recuperado de <http://www.igme.es/patrimonio/GeoparquesIGME2014-1.pdf>.

Carcavilla, Luis y Palacio, Jaime (2010). Aportación española al patrimonio geológico mundial. Madrid: Instituto Geológico y Minero de España.

Carcavilla, luis; Belmonte, Ánchel; Durán, Juan José e Hilario, Asier (2011). «Geoturismo: Concepto y perspectivas en España». Enseñanza de las Ciencias de la Tierra, 19 (1), 81-94.

Chicharro, Eva; Boixereu, Ester; Villaseca, Carlos y López-García, José Ángel (2011). «Contribución a la puesta en valor del patrimonio geológico y minero del Geoparque de las Villuercas: El Cerro de San Cristobal (Logrosán, Cáceres)». De Re Metallica, 17, 47-54.

Cueto, Gerardo J. (2016). «Nuevos usos turísticos para el patrimonio minero en España». Pasos: Revista de Turismo y Patrimonio Cultural, 14 (4), 1013-1026. $<$ https://doi.org/10.25145/j.pasos.2016.14.065>

Dowling, Ross K. y Newsome, David (eds.) (2006). Geotourism. Oxford: Elsevier y Butterworth Heinemann.

Farsani, Neda T.; Cohelo, Celeste y Costa, Carlos (2011). «Geotourism and geoparks as novel strategies for socio-economic development in rural areas». International Journal of Tourism Research, 13 (1), 68-81.

$<$ https://doi.org/10.1002/jtr.800> 
Fernández, Guillermina; Ramos, Aldo; Valenzuela, Silvia y Ricci, Susana (2015). "Geodiversidad, patrimonio minero y geoturismo: Propuesta de parque geominero en Argentina». Turismo y Sociedad, 17, 17-37.

<https://doi.org/10.18601/01207555.n17.02>

Fernández-Martínez, Esperanza; Hilario, Asier; Alcalá, Luis; Monasterio, Juan Manuel; Martínez, José Antonio y Santisteban, Carlos de (2014). «Actividades de divulgación del patrimonio geológico en geoparques». Enseñanza de las Ciencias de la Tierra, 22 (1), 61-68.

García, Francisco Javier; Delgado, Aquilino y Felicidades, Jesús (2013). «El turismo en la cuenca minera de Riotinto». Cuadernos de Turismo, 31, 129-152.

Geoparque Villuercas-Ibores-Jara (coord.) (2017). Geoparques: Los destinos más innovadores del turismo sostenible. Madrid: Foro Español de Geoparques y Global Geoparks.

- (coord.) (2018). Geoparques: Una ventana a la historia de la Tierra. Cáceres: Geoparques Mundiales de la Unesco en España.

Hernández Ortiz, Francisco (2018). «Las Minas de Rodalquilar». Revista Ph Instituto Andaluz del Patrimonio Histórico, 93, 32-46.

Hose, Thomas A. (2017). «The English Peak District (as a potential geopark): Mining geoheritage and historical geotourism». Acta Geoturística, 8 (2), 32-49.

Leite, Marcos Antonio; Leite, Kátia y Cardozo, Jasmine (2015). «Bases conceituais para entender geodiversidade, patrimônio geológico, geoconservaçao e geoturismo». Revista Ecuador, 4 (3), 48-68. Recuperado de <http://www.ojs.ufpi.br/index. $\mathrm{php} /$ equador/article/viewFile/3643/2119\#page $=28>$.

LLuRDÉs, Joan Carles (2016). «La relación entre gastronomía y geología: El papel de los geoparques en la difusión del patrimonio gastronómico. El caso del Geoparque de la Cataluña Central». En: García Marín, R. et al. (eds.). XV Coloquio Ibérico de Geografía: Retos y tendencias de la Geografía Ibérica. Murcia: Universidad de Murcia, AGE y APG, 614-626.

- (2017). «El paisaje minero, ¿patrimonio o inconveniente paisajístico?: El caso de la comarca del Bages (Barcelona)». Ería. Revista de Geografía, 2, año XXXVII, 151-167. <https://doi.org/10.17811/er.2.2017.151-167>

Llurdés, Joan Carles; Díaz-Soria, Inmaculada y Romagosa, Francesc (2016). «Patrimonio minero y turismo de proximidad: El caso de Cardona». Documents d'Anàlisi Geogràfica, 62 (1), 55-77. <https://doi.org/10.5565/rev/dag.231>

Marchán, Carmen y Sánchez, Alejandro (2013). "Consideraciones sobre el patrimonio minero desde la perspectiva de un servicio geológico nacional». Boletín Panaerense de Geociencias, 70, 77-86. <https://doi.org/10.5380/geo.v70i0.31502>

Meléndez-Hevia, Guillermo; Cardozo, Jasmine y Carcavilla, Luis (2017). "Geoturismo: El paso de un recurso a un atractivo». TerraPlural, 11 (2), 327-337.

Palacio, José Luis (2013). "Geositios, geomorfositios y geoparques: Importancia, situación actual y perspectivas en México». Investigaciones Geográficas: Boletín del Instituto de Geografía UNAM, 82, 24-37. <https://doi.org/10.14350/rig.32817>

Palacios, Antonio J. e Hidalgo, Carmen (2009). «Una aproximación al concepto de puesta en valor del patrimonio industrial» Revista Terra Plural, 3, 171-185. <https://doi.org/10.5212/terraplural.v.3i2.171186> 
Pardo, Carlos J. (2010). «El patrimonio industrial en España: Análisis turístico y significado territorial de algunos proyectos de recuperación». Boletín de la Asociación de Geógrafos Españoles, 53, 239-264.

Puig, Joan S.; Mata-Perelló, Josep M.; Bravo, Francisco; Vilatella, Jaume y FONT, Josep (2016). «La minería y el patrimonio minero en el Geoparque del Maestrazgo: Comarca de las Cuencas Mineras». En: Mata-Perelló, Josep M. y MonASTERIO, Manuel (coords.). La minería y la geología ambiental: Herramientas para el desarrollo sostenible, para el presente y para el futuro. Madrid: Geoparque Molina-Alto Tajo, SIGMADOT y SEDPGYM.

Ramsay, Tony (2016). "Geoparks: Sustainable tourism destinations for all!». Europeam Geoparks Magazine, 14, 3.

Rybár, Pavol y Śtrba, Lubomír (2016). «Mining tourism and its position in relation to other forms of tourism». En: Ugolini, F. et al. (eds.). Proceedings on the GEOTUR 2016: International Conference on Geotourism, Mining Tourism, Sustainable Development, and Environmental Protection. Florencia: IBIMET-CNR, 2-7.

SÁNCHEZ, José Luis (2011). "Geoparques y áreas naturales protegidas: Una visión desde la conservación, identidad y participación social». Investigación Ambiental Ciencia y Política Pública, 3 (2), 44-51.

Sánchez, José Luis; Arredondo, M. Concepción; Leyva, Claudia; Ávila, Guillermo; Figueroa, Carlos y Mata Perelló, Josep Maria (2013). «Determinación del patrimonio geológico, cultural e histórico en la creación de geoparques como instrumento de conservación y desarrollo local». De Re Metallica, 20, 47-54.

Stoffelen, Arie y Vanneste, Dominique (2015). «An integrative geoturism approach: Bridging conflicts in tourism landsacape research». Tourism Geographies, 17 (4), 544-560. <https://doi.org/10.1080/14616688.2015.1053973>

UNESCO (2016). Unesco Global Geoparks: Celebrating Earth Heritage, Sustaining local Communities. París: Unesco.

Valenzuela, Manuel; Palacios, Antonio J. e Hidalgo, Carmen (2008). «La valorización turística del patrimonio minero en entornos rurales desfavorecidos: Actores y experiencias». Cuadernos de Turismo, 22, 231-260.

Vотн, Andreas (2008). «Los geoparques y el geoturismo: Nuevos conceptos de valorización de recursos patrimoniales y desarrollo regional». En: Galve, A. (ed.). XI Coloquio Ibérico de Geografía. Alcalá de Henares: Universidad de Alcalá, 1-15.

VVAA (2006). Por una nueva cultura del Territorio. Recuperado de <http://www.geografos.org/images/stories/interes/nuevacultura/manifiesto-por-una-nueva-culturadel-territorio-d5.pdf>.

- (2016). Cardona, un destino diferente. Recuperado de <https://www.elnacional.cat/ es/cultura/cardona-castillo-mina-sal_107459_102.html>.

Walliss, Jilliam y KoK, Katherine (2014). «New interpretative strategies for the geotourism: An exploration of two Australiam mining sites». Journal of Tourism and Cultural Change, 12 (1), 33-49.

<https://doi.org/10.1080/14766825.2013.868902>

Recursos electrónicos [Consultas: 15 de octubre de 2018]

Carta de El Bierzo para la Conservación del Patrimonio Minero de España. <https:// ipce.culturaydeporte.gob.es/dam/jcr:9150e4a0-fb5b-40f9-8b42-df8f70187f27/ carta-del-bierzo-layout1.pdf> 
Carta de Nizhny Tagil sobre el Patrimonio Industrial. <http://www.international. icomos.org/18thapril/2006/nizhny-tagil-charter-sp.pdf>

Declaración de Arouca. <http://viajealasostenibilidad.org/documentos/declaracionde-arouca/>

Declaración de Girona sobre la protección del patrimonio geológico. <http://www. igme.es/patrimonio/links/declaracionGirona.htm>

EGN (European Geoparks Network). <http://www.europeangeoparks.org/>

Foro Español de Geoparques. <http://geoparques.eu/>

GGN (Global Geopark Network). <http://www.globalgeopark.org/>

IGME (Instituto Geológico y Minero de España). <http://www.igme.es/>

Junta de Andalucía. <http://www.juntadeandalucia.es/>

Ley 18/1985 de Patrimonio Histórico Español. BOE núm. 155, de 29/06/1985. <https://www.boe.es/buscar/act.php?id=BOE-A-1985-12534>

Ley 42/2007 del Patrimonio Natural y de la Biodiversidad. BOE núm. 299, de 14 de diciembre de 2007. <https://www.boe.es/buscar/doc.php?id=BOEA-2007-21490>

Minas de Sierra Morena. <http://www.minasdesierramorena.es/guia-de-campo/ conjuntos-mineros/cerro-del-hierro/>

mNACTEC (Museu de la Ciència i de la Tècnica de Catalunya). <http://mnactec. $\mathrm{cat} / \mathrm{es} />$

Red Ibérica de Espacios Geomineros. <http://patrimonigeominer.eu> 
